\title{
O PARADIGMA DA ATUAÇÃO DOS MILITARES NAS QUESTÕES DE MIGRAÇÃO FORÇADA: UM OLHAR INTERDISCIPLINAR ENTRE A POLÍTICA E A PSICOLOGIA
}

The paradigm of the military intervention in issues of forced migration: an interdisciplinary view between Politics and Psychology

\author{
Hiller Silva Eneterio* \\ Núbia Gonçalves da Paixão Eneterio** \\ Arlete Mendes da Silva***
}

\begin{abstract}
Resumo. Diante um diálogo interdisciplinar entre a Política e a Psicologia, esse artigo intenta discutir a relação entre a ação dos militares, nas respostas humanitárias às migrações forçadas, e a suscetibilidade da saúde psíquica do indivíduo deslocado. A metodologia consistiu de revisão bibliográfica e pesquisa documental, instrumentalizada pela proposta de Japiassu. Os resultados indicam que o modo como se estrutura a atuação participativa das forças armadas na especificidade de cada contexto, acrescido da percepção individual positiva ou negativa, acerca das entidades como mediadoras de proteção, irá determinar como se dará a suscetibilidade da saúde psíquica do deslocado e a possibilidade de proporcionar o alívio às condições geradoras de trauma.
\end{abstract}

Palavras-chave: migrações forçadas; interdisciplinaridade; forças armadas; saúde psíquica.

Abstract. Faced with an interdisciplinary dialogue between politics and
psychology, this article aims to discuss the relationship between military
action in humanitarian responses to forced migration and the maintenance
of the psychic health of the migrant. The methodology consisted of
bibliographic review and documentary research, instrumented by the
proposal of Japiassu. The results indicate that the way in which the
participatory action of the armed forces is structured in the specificity of
each context plus the positive or negative individual perception about the

Professor do Centro de Instrução e Adaptação da Aeronáutica (CIAAR) e pesquisador da Universidade da Força Aérea (UNIFA). Anápolis - GO, Brasil. E-mail: hillersilva@yahoo.com.br. Orcid: 0000-0002-1329-5878.

** Professora adjunta do Centro Universitário de Anápolis (UniEvangélica). Anápolis - GO, Brasil. E-mail: nubiapsia mbiental@gmail.com. Orcid: 0000-0002-3934-6709.

*** Professora titular e pesquisadora da Universidade Estadual de Goiás. Anápolis - GO, Brasil. E-mail: arlete.mendes@ueg.br. Orcid: 0000-0003-1524-9610. 
entities as mediators of protection, will determine how the susceptibility of the psychic health of the displaced person will occur and the possibility of providing the relief to the conditions generating trauma.

Keywords: forced migrations; interdisciplinarity; armed forces, psychic health.

\section{Introdução}

A Operação Acolhida é um instrumento de ação do Estado brasileiro, frente ao fluxo de venezuelanos ingressando no Brasil. A articulação envolve dezesseis órgãos federais e diversas agências da ONU (Campos, 2018; Fonseca, 2018).

Referente a essa ação governamental, um relatório técnico apresentado pelo Conselho Nacional de Direitos Humanos (CNDH), em maio de 2018, suscitou opiniões polarizadas entre instituições do nível federal. Contrapondo a Casa Civil, o Ministério da Defesa e a Presidência da República, que celebraram o sucesso da operação, as críticas constantes do relatório apontaram a "[...] característica nociva de 'militarizar a resposta humanitária' dada à questão migratória no Brasil, ao delegar às Forças Armadas (doravante, FAA) papel central na questão" (Charleaux, 2018, n. p., grifo do autor).

Muitas organizações e indivíduos têm opiniões diversas sobre suas disposições de se envolverem com forças militares, especialmente em ambientes de migrações forçadas, quando até mesmo as tropas da ONU podem ser vistas como parte do eventual conflito originador da evasão. Em desastres ambientais, entretanto, quando a ênfase está nas atividades imediatas de salvamento de vidas e no alívio do sofrimento, há uma maior aceitação de se trabalhar ao lado de militares.

Retornando ao exemplo brasileiro, Charleaux (2018) aponta a afirmação constante do relatório técnico do $\mathrm{CNDH}$ : "As Forças Armadas são responsáveis pela defesa do Brasil e, se eles assumem as funções sociais e humanitárias no campo da imigração, estão demonstrando que o governo brasileiro vê o imigrante como uma pessoa da qual ele precisa se defender".

Com isso, evidencia-se a suscetibilidade psicológica do indivíduo, em condição de migração forçada, ao se deparar com forças armadas conduzindo a resposta estatal a sua situação. Essa percepção dual sobre tais instituições, uma vez que a própria simbologia bélica apresenta intrinsecamente uma conotação traumática, também reflete a fragmentação de aspectos psicossociais basilares, tais como símbolos, identidade e cultura (Dantas et alii, 2010; Grinberg, Grinberg, 1989; Martins-Borges, 2013).

O temor de ondas de violência nas situações de deslocamentos humanos está presente nas postulações daqueles que defendem o auxílio das FAA nessas 
condições, a fim de "[...] ajustar o sujeito ao meio social" (Scarparo, Torres, Ecker, 2014, p. 61, grifo do autor). Por outro lado, o sentimento de proteção proporcionado (e exemplificado) pela presença militar é visto como essencial para a proteção psicológica, no sentido de que a presença de indicadores de proteção serve para reduzir o estresse inerente à observação subjetiva da eficácia do suporte social que está sendo dedicado àquele deslocado, bem como vincular o sentimento de cuidado por pertencimento a um grupo igualitário (Bauman, 2005; De Antoni, Barone, Koller, 2007; Cowan, Cowan, Schulz, 1996).

Em presença desse panorama, no qual intervêm processos e obliquidades de análises dos diversos campos do saber, evidencia-se a necessidade de uma visão fundada em um entendimento comum e holístico dessa realidade. Portanto, diante da proposição de um viés interdisciplinar, fundamentado no diálogo entre a Política e a Psicologia, esse artigo objetiva discutir a relação entre a ação participativa de militares, nas respostas humanitárias às migrações forçadas, e a suscetibilidade da saúde psíquica do indivíduo deslocado.

Com isso, a busca de uma releitura ampla motiva a cerne deste trabalho, de modo a estabelecer intencionalmente nexos e vínculos ${ }^{1}$ entre as disciplinas elencadas. Trata-se, então, de uma pesquisa interdisciplinar de natureza qualitativa, baseada em uma revisão documental e bibliográfica que adota a metodologia proposta por Japiassu (1976).

O artigo está estruturado em quatro seções, precedidas por esta Introdução. A primeira seção expõe como se dá a atuação dos militares no contexto elencado. Na segunda seção, apresentam-se as colocações teóricas sobre a suscetibilidade da saúde mental do migrante forçado. As confluências conceituais, evidenciadas nas seções anteriores, são discutidas na terceira seção. Por derradeiro, a última seção exibe as considerações finais.

\section{A intervenção militar nas questões humanitárias de mobilidade}

\section{humana}

Inicialmente, faz-se forçosa para esta investigação, fins de delimitação e emprego do termo "migração forçada"2 , a discussão sobre tal categoria.

A adoção da expressão é recorrente na literatura, porém é desaconselhada pelo Alto Comissariado das Nações Unidas para os Refugiados - ACNUR, órgão

\footnotetext{
1 De modo a se delimitar a inter-relação entre as áreas do conhecimento tratadas nesta pesquisa, as conexões interdisciplinares concentrar-se-ão na forma de atuação participativa das forças militares e na percepção do sujeito sobre das entidades como intercessores de proteção.

2 Ao se apropriar do construto que envolve vários fenômenos de mobilidade humana, este artigo considerará "migração forçada" como os movimentos involuntários, enfatizando os transfronteiriços, em decorrência de desastres ambientais, conflitos, fome, ou projetos de desenvolvimento em larga escala.
} 
que considera tal termo amplo, generalista e que abrange variados fenômenos de deslocamentos, motivados por desastres ambientais, conflitos, fome, ou projetos de desenvolvimento em larga escala, entre outros fatores. A visão da Agência ressalta o imperativo de foco nas necessidades específicas de cada categoria, em especial às dos refugiados.

No entanto, a Organização Internacional para as Migrações - OIM, no seu Glossário sobre imigração, de 2009, estabelece a construção da expressão, ao descrevê-la como:

Termo geral usado para caracterizar o movimento migratório em que existe um elemento de coação, nomeadamente ameaças à vida ou à sobrevivência, quer tenham origem em causas naturais, quer em causas provocadas pelo homem (por ex., movimentos de refugiados e pessoas internamente deslocadas, bem como pessoas deslocadas devido a desastres naturais ou ambientais, químicos ou nucleares, fome ou projetos de desenvolvimento). (OIM, 2009)

Concordante, Milesi (2005, p. 1), ao apontar a premência da reflexão sobre esta circunstância das migrações forçadas, em suas diversas manifestações e causas, compara as migrações forçadas às condições de refúgio:

Com a mesma intensidade, mas em circunstâncias diversas, ocorrem outros deslocamentos forçados devido a razões econômicas imperiosas, pobreza, violação de direitos, fome e mesmo desastres naturais. Não resta dúvida, nestas circunstâncias, que se configura a condição do migrante forçado [...].

As migrações, vistas como fenômeno social, apresentam diferentes visões sobre os motivos que originam a mobilidade humana. O Professor Anthony $\mathrm{H}$. Richmond, no livro Immigration and ethnic conflict, revisita os teóricos clássicos e pontua que estes autores - considerando Malthus, Marx, Durkheim e Weber - concebiam a mobilidade populacional como um fator resultante do capitalismo, sendo a migração em si uma preocupação secundária de suas pesquisas (Richmond, 1988).

Em um momento posterior, após as abordagens que grifavam a mobilidade humana como uma consequência das transformações políticas e econômicas do período pós-guerra, ocorreu uma reconfiguração dos fluxos migratórios internacionais, fomentando estudos que focavam o indivíduo migrante e suas relações, tratando menos das causas do fenômeno, sem, contudo, desconsiderar os conflitos bélicos, perseguições e as crescentes tragédias naturais como geradores das migrações forçadas, além das aposições sobre mobilidade destinada a outros países menos desenvolvidos. Naquele cenário, destacaram-se os trabalhos de Castles \& Kosak (1973) acerca da Europa e Portes (1981), aplicado aos Estados Unidos (apud Sasaki, Assis, 2000). 
Com efeito, tornaram-se relevantes as interações dos atores globais quanto à percepção dos fenômenos migratórios, uma vez que passam a pautar tópicos cruciais da agenda internacional, reiterando a latente atenção às condições que destacam os deslocados ambientais e refugiados.

Dessa forma, os bens públicos globais ${ }^{3}$ compõem o que se convencionou tratar como problema de relações exteriores. Nesse painel, é evidente o atual interesse político dos países que visam obter, ou mesmo manter, influência nas decisões que as instituições internacionais promovem, ressaltando-se, como condições sine qua non: a obviedade de se renovar as alianças preexistentes, o comprometimento com as instituições internacionais (exemplificadas pela ONU), a renovação desse comprometimento e a padronização das ações do Estado frente ao Direito Internacional Humanitário (DIH) (Armitage, Nye, $2007)^{4}$.

Pierluigi Musarò, tratando do discurso de Filippo Grandi, do ACNUR, em 8 de março de 2016, apõe que Grandi não mencionou em que medida, a militarização das fronteiras foi explicitamente vinculada a noções de humanitarismo. "No entanto, eu acho que ele está ciente de que o foco atual em ambos os aspectos, humanitários e relacionados à segurança do fenômeno, sugerem uma lógica mais complexa de ameaça e benevolência que permite uma resposta de segurança humanitária" (Musarò, 2016, p. 3).

Logo, o aumento na incidência de desastres naturais e a tendência simultânea para a militarização da ajuda humanitária em situações de conflito são aspectos que caracterizam o também crescente papel dessas instituições na resposta estatal às emergências humanitárias (Hofmann, Hudson, 2009; Madiwale, Virk, 2011).

O envolvimento das FAA nestes termos é evidente devido às capacidades e aos atributos inerentes à utilização dos meios militares. Com isso, a comunidade humanitária internacional reconhece que os militares desempenham um papel vital na resposta a desastres, nos casos de incapacidade estatal, pois "[...] podem fornecer entre outras coisas, uma capacidade de busca e resgate, apoio logístico, mão-de-obra especializada, perícia e recursos materiais inigualáveis e, ocasionalmente, segurança para os trabalhadores humanitários" (Madiwale, Virk, 2011, p. 1086). Ressalta-se

3 Relevante construção conceitual, os bens públicos globais podem ser exemplificados, numa acepção simplória, pela água, a terra e o ar puro; e, em um plano mais pragmático, a camada de ozônio, o controle de epidemias e dos efeitos poluentes transfronteiriços. Ainda se refere às respostas de cooperação internacional que ultrapassam interesses nacionais, como às privações humanas (a miséria ou as violações dos direitos fundamentais podem levar à emigração) (Kaul, 2000).

4 Considerando-se o panorama de estudo do autor, uma vez que esse comprometimento atual não é tão óbvio, como demonstra a saída de alguns países do Pacto Global para a Migração da ONU. 
ainda que, considerando os instantes iniciais do que será um fator originário da mobilidade, as forças armadas nacionais tendem a ser atores com os melhores recursos para alcançar áreas afetadas rapidamente e desempenhar um papel crítico na redução da perda imediata de vida.

Harkin (2004, p. 6, grifo do autor) corrobora com tais postulações e acrescenta que:

Com recursos de logística e pessoal em constante prontidão (embora nem sempre disponíveis para operações de resposta a desastres) e, em alguns casos, suas próprias reservas de itens de socorro, as forças militares são capazes de reagir com rapidez.

No entanto, o assunto mostra-se controverso, uma vez que a distinção dos papéis entre os atores em questão pode comprometer a neutralidade e a independência, restringindo o acesso humanitário e aumentando a insegurança, principalmente nesses ambientes em que o deslocamento forçado se deu em consequência de subversões.

Segundo Madiwale e Virk (2011), os princípios humanitários e a própria segurança são temas de maior recorrência nas relações civis-militares. Pelo fato das FAA serem instrumentos de estado, há uma preocupação latente de que, ao serem mobilizados para atuarem em condições migratórias, decorrentes de desastres naturais, política e de segurança, os militares podem, por vezes, ter tal situação sobrepondo-se às considerações humanitárias. Por exemplo, os humanitaristas temem que os métodos utilizados pelas autoridades militares para realizar avaliações nas comunidades locais possam desafiar sua capacidade de prestar assistência aos mais vulneráveis de forma responsável e imparcial.

Quanto a esse receio da atuação dos militares, nota-se que os atores humanitários veem com cautela esses envolvimentos e que tais ações são "[...] ineficientes, inapropriadas, inadequadas e dispendiosas, contrárias aos princípios humanitários e conduzidas por imperativos políticos ao invés da necessidade humanitária" (Hofmann, Hudson, 2009, p. 30).

A relação problemática entre humanitarismo e política já havia sido claramente descrita, em 1999, por James Orbinski, do Médecins Sans Frontières, por ocasião de sua palestra sobre o Nobel: "O humanitarismo não é uma ferramenta para acabar com a guerra ou para criar a paz. É uma resposta do cidadão ao fracasso político. É um ato imediato, de curto prazo, que não pode apagar a necessidade de longo prazo da responsabilidade política" (Musarò, 2016, p. 4). Nesse discurso, o premiado critica as intervenções militares, então denominadas de humanitárias.

Musarò ainda se refere à visão dialética das imagens da operação Mare Nostrum, as quais "[...] provocam simpatia pelos soldados e pena dos migrantes" 
(2016, p. 7), uma vez que exploram uma situação na qual o espectador é posicionado como o possível salvador, enquanto os corpos resgatados são o outro. O controle de fronteiras é redefinido dentro de uma imaginação moral que enfatiza a vulnerabilidade humana, representada por imagens midiáticas de militares entregando ajuda a migrantes resgatados e mulheres com bebês pequenos.

A questão dos fluxos migratórios é aqui entendida como uma viagem sem destino, como um trágico jogo do destino. Como protagonistas de uma crise que vem do nada, os migrantes são retratados ao mesmo tempo como sujeitos que são forçados a se colocar em perigo - partindo de barcos inseguros - e como sujeitos em risco (de morte e tráfico) que precisam ser salvos. (Musarò, 2016, p. 7)

Assim, a refração das questões envolvendo a relação militar e humanitária é, nesse viés, tratada quase antagonicamente e a narrativa esteia uma ontologia intricada de desigualdade que atribui hierarquia a valores específicos e avaliações da vida humana, em vez de promover a solidariedade em nome da dignidade humana. "Ao contrário, corre o risco de apoiar a governança global neoliberal no estabelecimento de uma geografia moral assimétrica (em termos de agência e dignidade) do mundo" (Musarò, 2016, p. 8, grifo do autor).

As divergências sobre as abordagens humanitárias e militares, apesar de conterem objetivos compartilhados, muitas vezes criam tensões entre os atores. Torna-se, assim, imperativa uma visão ampla sobre os processos de respostas emergenciais no sentido lato.

Além do ACNUR, o Escritório da ONU para Coordenação de Assuntos Humanitários (UNOCHA) agem frequentemente como organizações internacionais líderes para apoiar e coordenar o planejamento e as operações das OAH durante uma emergência complexa (OTAN, 2003).

Quanto às FAA, há uma centralização na dissuasão ou na segurança física, que pode levar a sítios fortificados e à presença de armas nos pontos de distribuição. Por outro lado, os humanitários, particularmente as ONGs e o Movimento Internacional da Cruz Vermelha e do Crescente Vermelho, tendem a confiar na segurança baseada na aceitação, que busca obter o consentimento de todas as partes interessadas em uma área operacional e proíbe a presença de armas nos pontos de distribuição (Madiwale, Virk, 2011).

Estas pontuações sobre o papel dos militares na resposta humanitária internacional ampla são ainda pautadas e orientadas por duas diretrizes, de reconhecimento global: as Diretrizes sobre o Uso de Ativos Militares e de Defesa Civil em Desastres - Diretrizes de Oslo - e as Diretrizes sobre o Uso de Ativos Militares e de Defesa Civil para Apoiar as Atividades Humanitárias das Nações Unidas em Emergências Complexas - Diretrizes MCDA (Military and 
Civil Defense Assets) (Madiwale, Virk, 2011). Ambos os conjuntos de diretrizes expõem o uso de ativos de militares e de defesa civil, em emergências complexas e desastres naturais, como meio de último recurso, limitado por quadros políticos internacionais. As diretrizes de Oslo afirmam ainda a importância dos princípios humanitários e o papel primordial dos atores civis no socorro em casos de desastres (Harkin, 2004; OCHA, 2007; Madiwale, Virk, 2011).

O princípio de último recurso destaca os meios de defesa militares como uma ferramenta complementar a mecanismos existentes para necessidades específicas, em resposta a uma violação de assistência humanitária $(\mathrm{OCHA}$, 2007). Assim, quatro critérios são necessários para a adoção desses meios: a) não existir nenhum recurso civil alternativo adequado para a situação; b) a urgência da tarefa demandada requer uma ação imediata; c) o controle civil sobre a utilização dos meios militares; e d) a utilização de meios militares para apoiar atividades humanitárias é claramente limitado no tempo e escala (Metcalfe, Haysom, Gordon, 2012).

O Comitê Internacional da Cruz Vermelha (CICV) percebe tal princípio como fundamental. Porém, como professam Hofmann e Hudson (2009), de uma perspectiva operacional, pode, no entanto, ser difícil de aplicá-lo na prática, uma vez que em situações calamitosas, a premência no atendimento demanda em um pragmatismo que geralmente prevalece.

\section{A suscetibilidade da saúde mental do migrante forçado}

Segundo De Antoni, Barone e Koller (2007), o risco tem sido empregado, no campo da saúde mental, com o sentido de estressor, o qual poderá promover comportamentos inesperados. Enfatiza-se que, em situações de sofrimento psíquico, a gravidade da violência alcança, integralmente, os processos de desenvolvimento físico, psicológico e social dos envolvidos, do sistema como um todo e da sociedade a qual esse sistema pertence.

No contexto de mobilidade humana, diversos aspectos individuais promovem no migrante a acepção da sua autocondição. Tais aspectos, ao corroborarem para a proteção psíquica do sujeito, são chamados fatores de proteção e formam um conjunto único de estratégias internas de adaptação e/ou superação de crises.

Os autores ainda ressaltam que, diante de geradores de estresse - como situações de deslocamentos forçados - o suporte social pode ter influência para reduzir essa condição, a qual também pode variar de acordo com o nível de outro fator de proteção, o qual é exemplificado pela autoestima (De Antoni, Barone, Koller, 2007). 
Esses fatores de proteção, ao serem tratados, resultam em indicadores de proteção que, por sua vez, são classificados, geralmente, em dois grupos: os fatores pessoais, "evidenciados pelo componente biológico, como a saúde física e o temperamento e pelas experiências com o meio ambiente social, como a autoestima e a confiança; e os recursos do ambiente, demonstrados pelas condições socioeconômicas e pela rede de apoio social e afetiva existente" (De Antoni, Barone, Koller, 2007, p. 126). Em outra concepção, devido aos seus efeitos nas relações e nos resultados específicos, o risco é visto de modo dinâmico, ou seja, qualquer variável pode atuar como indicador de risco em uma determinada situação (Cowan, Cowan, Schulz, 1996; Gore, Eckenrode, 1996). Pianta e Walsh (1996) acrescentam que uma situação de risco pode ser transformada para causar resultados positivos ou negativos.

Della Pasqua e Dal Molin (2009, p. 4) esclarecem que "emigrar pode ser um processo que possui níveis de estresse tão intenso que muitas vezes superam as capacidades de adaptação dos seres humanos". Para a compreensão desse enfrentamento, há uma convergência das bases teóricas da Psicologia para os conceitos de identidade, cultura e saúde psíquica, relação ${ }^{5}$ de amplo espectro na literatura, a qual é abordada en passant neste trabalho para uma melhor abrangência contextual.

Assim sendo, nesse fenômeno de deslocamentos compulsórios, enquanto relacionado a fatores políticos e sociais, guerras e catástrofes naturais, mesmo relevando o impacto que se apresenta de forma diferenciada em cada caso migratório, percebe-se uma ruptura de identidade devida à perda da compreensão dos sentidos para uma mesma realidade e suas normas sociais, englobando uma contradição entre esta e o objeto idealizado. E, ocorrendo essa ruptura identitária, resultante do distanciamento da cultura fundadora, gera-se "[...] sofrimento psicológico diretamente ligado às perdas e ao traumatismo ao qual foram submetidas" (Martins-Borges, 2013, p. 151).

Essas postulações da autora, provenientes da Psicologia Intercultural, são reiteradas pela abordagem psicanalítica de que acontecimentos traumáticos podem romper o escudo protetor do aparelho psíquico e provocar um distúrbio de grande magnitude no funcionamento energético orgânico. Considera-se que há ainda uma intensa percepção de abandono, à medida que os referentes culturais e simbólicos de origem passam a ser questionados ou, até mesmo invalidados, nas situações de migração forçada acatadas neste trabalho. Os autores ainda avaliam que a mortificação dos pontos de identificação dos

\footnotetext{
A aculturação é permeada por traços de representações sociais, políticas, culturais e psicológicas. Ao se referir às mudanças que ocorrem devido ao contato com as dissimilaridades culturais com outros sujeitos, sejam nos níveis de análise da sociedade ou mesmo no indivíduo, esse termo engloba, em sua etimologia, a relação direta desta cultura, porém, associado à identidade e saúde mental, nos seus mais variados significados e focos de pesquisa (Kim, 1980; Lakey, 2003).
} 
indivíduos que se reconhecem como pertencentes a um grupo social e a uma determinada cultura favorece o aparecimento de relevantes crises psíquicas (Carignato, Rosa, Berta, 2006; Freud, 1920/1976).

A conexão com o outro (alteridade), aliada ao processo de reflexão e observação simultâneas, é a base da formação e do senso de identidade (Dantas et alii, 2010; Grinberg, Grinberg, 1989). Freud ainda realça os estímulos externos como agentes que podem fragmentar essa base e senso de identificação, vistos como escudos protetores ou barreiras.

Descreveremos como traumáticas quaisquer excitações provindas de fora que sejam suficientemente poderosas para atravessar o escudo protetor. Um acontecimento como um trauma externo está destinado a provocar um distúrbio em grande escala no funcionamento da energia do organismo e a colocar em movimento todas as medidas defensivas possíveis. (Freud, 1920/1976, p. 49, grifo do autor)

Dias (2005) concorda e acrescenta que as rupturas resultantes das mudanças do quadro externo de referência, simultaneamente, por efeito de ricochete, causam a ruptura do quadro interiorizado do próprio do indivíduo. A autora aduz que a aculturação englobará a percepção do sujeito no que diz respeito à habitação, legalização, os apoios e assistência prestados pelo ente receptor. Ressalta ainda que o migrante, na sociedade que o acolheu, irá ter alterado o seu modo de processar as codificações culturais, sensações, percepções e representações, estabelecendo relações por meio de códigos de grande complexidade.

Com efeito, ao centrar-se a migração na pessoa, "confere-se protagonismo ao sujeito que a pratica e como cada indivíduo é único, a participação no acontecimento tem a sua marca, sendo o inverso também verdadeiro, isto é, em si próprio existirão reflexos do ato praticado" (Dias, 2005, p. 8).

Expostos os olhares sobre as categorias identidade, cultura e saúde mental, soma-se a captação dos termos cuidado e liberdade, a fim de ser articulado o sentido da existência com as experiências de sofrimento psíquico no panorama elencado.

A construção do que é percebido como adequado à realidade, invariavelmente é de cunho subjetivo. Assim, o sofrimento produzido, em um panorama que se apresenta compulsório àquele deslocado, será processado de modos diferentes em cada sujeito (Santos, Sá, 2013).

O sofrimento existencial é então relacionado à restrição do sentido e da liberdade, segundo Heidegger (2009). E a percepção do que está trazendo cuidados para o sujeito é pontuada pelo autor como aquilo que traz alívio ao estresse, independentemente da forma que venha a se apresentar tal cuidado. 


\section{A influência da atuação das forças armadas na suscetibilidade psicológica do migrante}

Com o intuito de se discutir a relação entre a ação participativa das FAA e a suscetibilidade da saúde psíquica do indivíduo deslocado, nas condições de migrações forçadas, foi utilizada a metodologia interdisciplinar de Japiassu (1976).

Nas discussões acerca do emprego das FAA em ações junto aos deslocamentos forçados, mostra-se, por intermédio das postulações de Madiwale e Virk (2011) e Harkin (2004), que o emprego dessas instituições se dá, de forma pragmática, devido as suas capacidades, das quais se destacam a logística e a mão-de-obra especializada. Estes meios, por vezes, expõem uma predominante inépcia estatal de prover outros meios. Há ainda um consenso dos autores no sentido de que a prontidão típica dos meios militares é relevante para a rapidez ao atendimento para perda de vidas, neste caso, considerando-se, principalmente, os deslocamentos por causas ambientais e as migrações em que o conflito armado possa vir a ser um problema de segurança humana.

Porém, tais capacidades não excluem os debates acirrados sobre as relações e limitações entre os princípios humanitários e a própria segurança. As inferências de Madiwale e Virk (2011) apontam uma recorrência de reticências, por parte dos agentes humanitários, sobre a interferência militar não abarcar princípios basilares do atendimento aos migrantes, como a imparcialidade.

Atualmente, em muitos países, as instituições militares são colocadas nas fronteiras para impedir, dificultar ou selecionar a entrada de refugiados, mesmo perante de migrações forçadas. Nesse sentido, a possível falta de imparcialidade não se apresenta como questão única, uma vez que, ao adentrar um país ilegalmente aquele migrante forçado tende a interpretar o militar do país receptor como um possível empecilho para a própria fuga, o que evidencia um fator estressor. As FAA nestes casos tendem a gerar uma percepção paradoxal de insegurança.

Reiterando a cautela com que o assunto é tratado pela comunidade humanitária, não somente na literatura, mas de forma predominantemente usual, Hofmann e Hudson (2009) consideram tais ações, promovidas pelos militares, portadoras de predicados negativos aos princípios humanitários mencionados. Tais ideias apresentam consonância com as asserções de Musarò (2016), as quais apontam que as organizações de apoio humanitário têm observado, no discurso sobre o controle de fronteiras, novas pontuações políticas e epistemológicas. O princípio do último recurso, quando observado pelo $\mathrm{CICV}$, acontece por métodos empíricos de tomada de decisão, os quais 
consideram que deva haver a participação das FAA, somente após esgotados os recursos estatais de atendimento.

Com efeito, a adoção de medidas efetivas para a consecução de objetivos políticos, independentemente de sua ideologia, origem ou metodologia, expõe um interesse hodierno para o atingimento dessas finalidades estatais. Assim, alude-se que a intenção política vigente é norteada pela imagem pública constante da agenda internacional das instituições humanitárias, relevando a condição migratória como meio de política, conforme apresentado por Armitage e Nye (2007) e corroborado por Musarò (2016), quem acrescenta que os focos humanitário e securitário apresentam mediações complexas e diferentes, mas que são respostas ao fenômeno. Pontua-se então o novo papel das FAA, as quais não são mais somente instrumentos de guerra, mas sim, ferramentas utilizadas para a promoção do status do Estado, visando sua projeção global.

A discussão caminha então para uma dicotomia acerca da forma estatal de se conduzir as ações humanitárias, em detrimento à pura necessidade altruísta de redução do sofrimento. Neste sentido, o debate ultrapassa o questionamento entre o humanismo e as forças militares, passando então a relacionar as ações humanitárias com a visão política de um determinado país, interação esta que também é caracterizada pela visão acadêmica - e pela aplicação prática de separação dos próprios termos humanitária e militar.

Todavia, essa distinção é discordante de diversos documentos oficiais, os quais tratam as operações humanitárias como parte das funções das FAA, exemplificados, no contexto brasileiro, pela Política Nacional de Defesa do Brasil, de 2012; e, internacionalmente, pela Doutrina de Cooperação CivilMilitar da OTAN (BRASIL, 2012; OTAN, 2003).

Ainda, a chamada geografia moral procura promover o controle das fronteiras explorando a vulnerabilidade humana e exaltando os agentes militares (Musarò, 2016). Porém, ao desafiarem a acepção de serem vítimas indefesas das estruturas de governança, os migrantes forçados reafirmam suas identidades sociais e políticas, posição contrária à exploração estatal e midiática de suas condições.

Porém, essa condição de ator ativo do sujeito no panorama de mobilidade humana compulsória não exime este deslocado de ser atingido em sua saúde mental, considerando as já clássicas discussões sobre identidade e cultura, conforme colocado por De Antoni, Barone e Koller (2007), Cowan, Cowan e Schulz (1996), Gore e Eckenrode (1996), Pianta e Walsh (1996), Dias (2005) e Della Pasqua e Dal Molin (2009). Os autores concordam que os fatores de proteção são influentes na percepção das condições biopsicossociais que 
envolvem essa situação de migração forçada, ressaltando-se a variação dessa percepção e suas consequências em cada indivíduo.

Embasando a condição latente de sofrimento mental que são decorrentes da condição de obrigatoriedade dos deslocamentos tratados neste trabalho, Martins-Borges (2013), Carignato, Rosa e Berta (2006), e Freud (1920/1976), aquiescem, dentro de suas análises no campo da Psicologia, e enaltecem a fragmentação da identidade, percebida na relação com o outro e a nova realidade, como potenciais condições traumáticas, como ainda reiterado por Dantas et alii (2010) e Grinberg e Grinberg (1989).

O estudo de Dias (2005) pontua dois fatores latentes sobre a condição migratória, a percepção do sujeito e suas decorrentes consequências sobre sofrimento mental: primeiro, somando-se às influências culturais e identitárias inerentes ao relacionamento psíquico migrante-migração, apresentam-se os construtos cuidado e liberdade, os quais, diante da visão de agente ativo do deslocado - agora plenamente considerada - influenciarão também o processo de aculturação, sopesando seus aspectos de habitação, legalização, e de apoios e assistência prestados. No segundo ponto de análise da autora em pauta, perante essa visão centrada no protagonista, a autopercepção sobre como o cuidado traz alívio às condições geradoras de trauma é fundamental para a reformulação da vida do migrante, asserção esta legitimada por Heidegger (2009).

Portanto, como colocam Gore e Eckenrode (1996), compreender de que forma esses mediadores atuam para abrandar os efeitos negativos do estresse ou do risco, é tarefa tão complexa quanto determinar o que é fator de proteção e adversidade para cada ser humano.

Por outro lado, o sentimento de proteção proporcionado (e exemplificado) pela presença militar é visto como essencial para a proteção psicológica, no sentido de que a presença de indicadores de proteção serve para reduzir o estresse inerente à observação subjetiva da eficácia do suporte social que está sendo dedicado àquele deslocado, bem como denotar o sentimento de cuidado por pertencimento a um grupo igualitário (Bauman, 2005; De Antoni, Barone, Koller, 2007; Cowan, Cowan, Schulz, 1996).

Como análise final desta reflexão, a retomada das diferenças inerentes a cada situação de deslocamentos forçados se mostra imperiosa, uma vez que as particularidades, oriundos de motivos econômicos extremos, pobreza, violação de direitos, fome e mesmo desastres naturais, serão parte fundamental da percepção do indivíduo. Mesmo diante das colocações de que é vital, em determinadas situações, o sentimento de proteção proporcionado pela presença das FAA, quando considerada a compulsoriedade tratada neste artigo e sopesando-se a presença de indicadores de proteção como redutor 
da condição de sofrimento mental, os fatores de proteção, como percebidos pelo sujeito, são então as ferramentas individuais para a superação ou para a adaptação diante da crise. Nesses casos, o modo como se estrutura a atuação participativa das FAA naquele contexto específico, acrescido da percepção positiva ou negativa acerca dessas entidades como mediadoras de proteção, sugere como se dará a suscetibilidade da saúde psíquica do indivíduo deslocado. Para além disso, deve ainda observar-se que, na maioria das vezes, a ótica e a condição do migrante, este posto como um estrangeiro que adentra em outro território, serão fatores determinantes dessa percepção.

\section{Considerações finais}

Face ao turbulento panorama das mobilidades humanas de caráter compulsório, este trabalho possibilitou um olhar interdisciplinar sobre a ação participativa dos militares em tais cenários e a influência dessa intervenção na saúde psíquica do indivíduo deslocado.

Verificou-se, inicialmente, de que forma o regramento internacional prevê a atuação das forças armadas junto aos processos migratórios, percebendo-se que há uma divergência de opiniões no que diz respeito ao emprego dos militares nas questões em pauta, uma vez que diversas entidades relacionadas ao humanitarismo entendem tais ações como uma incompetência dos estados em proverem outros meios para substituir as capacidades militares. Entende-se ainda que há uma hodierna acepção de que as ações humanitárias, em especial aquelas relacionadas aos deslocamentos ambientais e ao refúgio, permeiam a agenda internacional dos estados, como modo de promoção político no cenário global.

Na releitura proposta, o estabelecimento interdisciplinar dos nexos entre a Política e a Psicologia propiciou a compreensão de que o modo como se estrutura a atuação participativa das FAA na especificidade de cada contexto, acrescido da percepção individual positiva ou negativa, acerca das entidades como mediadores de proteção, irá determinar como se dará a suscetibilidade da saúde psíquica do deslocado, bem como a possibilidade de proporcionar o alívio às condições geradoras de trauma.

Por derradeiro, ao ser atingido o objetivo geral proposto por esta investigação, notou-se, em adição, uma visão deturpada sobre o papel completamente passivo do migrante, bem como sobre um tratamento gerencial que confunde frequentemente responsabilidade política e humanitarismo. Destarte, expondo as limitações deste artigo, o assunto se mostra relevante para outras pesquisas sobre o tema, exemplificadas por como as FAA podem focar a formação dos próprios membros nas áreas dos Direitos Humanos, Antropologia Cultural, Psicologia, para que possam atuar com maior 
propriedade nos contextos de crises humanitárias, e reduzir eventuais fatores estressores.

E, uma vez evidenciada a necessidade da presença dos atores militares em situações em que é premente o atendimento à segurança humana (considerando-se as capacidades das FAA) e que há uma incapacidade estatal de provimento de outro recurso adequado, as organizações humanitárias têm a oportunidade e, talvez, o dever do trato com os militares para limitar os riscos intrínsecos a sua atuação e maximizar os benefícios potenciais ao sistema de resposta a desastres. Nestes casos, a questão não é mais se envolver com os militares, mas sim como e quando fazê-lo.

\section{Referências bibliográficas}

ARMITAGE, Richard Lee; NYE, Joseph Samuel Jr. A smarter, more secure America. Report of CSIS Commission on Smart Power. Washington: Center for Strategic and International Studies, 2007. Disponível em: <http://csis.org/files/media/ csis/pubs/071106_csissmartpowerreport.pdf > . Acesso em: 17.10.2018.

BAUMAN, Zygmunt. Modernidade e Ambivalência. Rio de Janeiro: Jorge Zahar, 2005.

BRASIL. Ministério da Defesa. Política Nacional de Defesa. Brasília: PND, 2012.

CAMPOS, Ana Maria. Ministro acompanha a situação dos migrantes venezuelanos em Roraima. Agência Brasil. 2018. Disponível em: <http://agenciabrasil.ebc. com.br/justica/noticia/2018-07/ministro-acompanha-situacao-dos-migrantesvenezuelanos-em-roraima $>$. Acesso em: 22.11.2018.

CARIGNATO, Taeco Toma; ROSA, Miriam Debieux; BERTA, Sandra Letícia. Imigrantes, migrantes e refugiados: encontros na radicalidade estrangeira. REMHU, Revista Interdisciplinar da Mobilidade Humana, v. 14, n. 26/27, p. 93118, 2006.

CASTLES, Stephen; KOSAK, Godula. Immigrant workers and class structure in Western Europe. London: Oxford University Press, 1973.

CHARLEAUX, João Paulo. Quais as críticas ao uso de militares na assistência a imigrantes. Nexo Jornal. 2018. Disponível em: <https://www.nexojornal.com. br/expresso/2018/05/23/Quais-as-críticas-ao-uso-de-militares-na-assistência-aimigrantes >. Acesso em: 24.10.2018.

COWAN, Philip; COWAN, Carolyn Pape; SCHULZ, Mark. Thinking about risk and a resilience in families. In: HETHERINGTON, E. Mavis; BLECHMAN, Elaine A. (orgs.). Stress, coping and a resiliency in children and families. New York: Psychology Press, 1996, p. 1-38.

DANTAS, Sylvia Duarte; UENO, Laura; LEIFERT, Gabriela; SUGUIURA, Marcos. Identidade, migração e suas dimensões psicossociais. REMHU, Revista Interdisciplinar da Mobilidade Humana, v. 18, n. 34, p. 45-60, 2010. 
DE ANTONI, Clarissa; BARONE, Luciana Rodriguez; KOLLER, Sílvia Helena. Indicadores de risco e de proteção em famílias fisicamente abusivas. Psic.: Teor. e Pesq., v. 23, n. 2, p. 125-132, 2007.

DELLA PASQUA, Leonardo; DAL MOLIN, Fábio. Algumas considerações sobre as consequências sociais e psicológicas do processo migratório. REMHU, Revista Interdisciplinar da Mobilidade Humana, v. 17, n. 32, p. 101-116, 2009.

DIAS, Maria Inês Silva. Uma Viagem Psicológica pela Migração. Psilogos, v. 2, n. 2, p. 6-12, 2005.

FONSECA, Carlos Eduardo. Histórico. Casa Civil. Presidência da República. 2018. Disponível em: <http://www.casacivil.gov.br/operacao-acolhida/historico>. Acesso em: 18.11.2018.

FREUD, Sigmunt. Além do princípio do prazer. Rio de Janeiro: Imago, 1976 (1920).

GORE, Susan; ECKENRODE, John. Context and process in research on risk, resilience and development. In: HAGGERTY, Robert J.; SHERROD, Lonnie R.; GARMEZY, Norman; RUTTER, Michael (orgs.). Stress, risk and resilience in children and adolecents: processes, mechanisms and interventions. Cambridge: Cambridge University Press, 1996, p. 19-64.

GRINBERG, Léon; GRINBERG, Rebeca. Psychoanalytic perspectives on migration and exile. New Haven: Yale University Press, 1989.

HARKIN, Clare. The 2004 Tsunami: civil-military aspects of the international response. London: Tsunami Evaluation Coalition, 2005. Disponível em: < http:// www.tsunami-evaluation.org/NR/> . Acesso em: 03.10.2018.

HEIDEGGER, Martin. Seminário de Zollikon. In: Medard Boss. Petrópolis: Vozes, 2009.

HOFMANN, Charles-Antoine; HUDSON, Laura. Military responses to natural disasters: last resort or inevitable trend? Humanitarian Exchange, n. 44, p. 2931, 2009.

JAPIASSU, Hilton. Interdisciplinaridade e patologia do saber. Rio de Janeiro: Imago, 1976.

KAUL, Inge. Cooperação internacional: a hora dos bens públicos globais. Le Monde diplomatique Brasil. 2000. Disponível em: < https://diplomatique.org.br/a-horados-bens-publicos-globais/>. Acesso em: 16.10.2018.

KIM, Jin K. Explaining acculturation in a communication framework: An empiric test. Communication Monographs, n. 47, p. 155-179, 1980.

LAKEY, Paul N. Acculturation: A review of the literature. Intercultural communication studies, Abilene Christian University, n. 12, v. 2, p. 103-118, 2003.

MARTINS-BORGES, Lucienne. Migração involuntária como fator de risco à saúde mental. REMHU, Revista Interdisciplinar da Mobilidade Humana, v. 21, n. 40, p. 151-162, 2013.

MADIWALE, Ajay; VIRK, Kudrat. Civil-military relations in natural disasters: A case study of the 2010 Pakistan floods. International Review of the Red Cross, v. 93, n. 884, p. 1085-1105, 2011. 
METCALFE, Victoria; HAYSOM, Simone; GORDON, Stuart. Trends and challenges in humanitarian civil - military coordination: a review of the literature. In: Humanitarian Policy Group Overseas Development, 2012. Disponível em: < https://www.odi.org/publications/6584-trends-and-challenges-humanitariancivil-military-coordination>. Acesso em: 22.10.2018.

MILESI, Rosita. Refugiados e migrações forçadas: uma reflexão aos 20 anos da declaração de Cartagena. Brasília: Instituto Migrações e Direito Humanos, 2005. Disponível em: <https://www.migrante.org.br/refugiados-e-refugiadas/ refugiados-e-migracoes-forcadas-uma-reflexao-aos-20-anos-da-declaracao-decartagena/> . Acesso em: 24.02.2019.

MUSARÒ, Pierluigi. Mare nostrum: the visual politics of a military-humanitarian operation in the Mediterranean Sea. Media, Culture \& Society, v. 39, p. 11-18, 2016.

ORGANIZAÇÃO DO TRATADO DO ATLÂNTICO NORTE (OTAN). AJP-9: NATO Civil-Military Co-operation (CIMIC) Doctrine. New York, 2003.

ORGANIZAÇÃO INTERNACIONAL PARA AS MIGRAÇÕES. Glossário sobre migração. Genebra: Organização Internacional para as Migrações, 2009.

PIANTA, Robert C.; WALSH, Daniel J. High-risk children school: Constructing, sustaining relationships. New York: Routledge, 1996.

PORTES, Alejandro. Modes of structural incorporation and present theories of laborimmigration. In: KRITZ, Mary et alii (eds.). Global trends in migration. New York: Center for Migration Studies, 1981, p. 179-197.

RICHMOND, Anthony H. Immigration and ethnic conflict. London: MacMillan Press, 1988.

SANTOS, Danielle de Gois; SÁ, Roberto Novaes de. A existência como "cuidado": elaborações fenomenológicas sobre a psicoterapia na contemporaneidade. Rev. Abordagem Gestalt., v. 19, n. 1, p. 53-59, 2013.

SASAKI, Elisa Massae; ASSIS, Gláucia de Oliveira. Teorias das migrações internacionais. In: II Encontro Nacional da ABEP 2000. Caxambu, outubro de 2000. Disponível em: <https://webcache.googleusercontent.com/ search?q=cache:K4FNoa-b9yoJ:https://www.pucsp.br/projetocenarios/ downloads/CDH/Teoria_das_Migracoes_Internacionais.pdf $+\& \mathrm{~cd}=10 \& \mathrm{hl}=\mathrm{pt}$ -

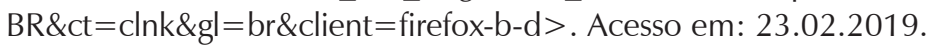

SCARPARO, Helena Beatriz Kochenborger; TORRES, Samantha; ECKER, Daniel Dall'Igna. Psicologia e ditadura civil-militar: reflexões sobre práticas psicológicas frente às violências de estado. Rev. Epos, v. 5, n. 1, p. 57-78, 2014.

UNITED NATIONS OFFICE FOR THE COORDINATION OF HUMANITARIAN AFFAIRS (OCHA). Directrices sobre el uso de recursos militares y de la defensa civil extranjeros en operaciones de socorro en casos de desastre - Diretrizes de Oslo, rev. 1.1. Nova York: Office for the Coordination of Humanitarian Affairs, 2007. 